Neural, Parallel, and Scientific Computations 28(2020), No.3, 161 - 181

\title{
IMPROVED FUZZY RULE SET DISTRIBUTED ALGORITHM BASED SMART WATER MANAGEMENT SYSTEM USING PROGRAMMABLE LOGIC CONTROLLER
}

\author{
G. KAVITHA ${ }^{1}$ AND R. VARATHARAJAN ${ }^{2}$ \\ ${ }^{1}$ Department of Electronics and Communication Engineering \\ Government College of Technology, Salem, India \\ kavitha@gcesalem.edu.in \\ ${ }^{2}$ Bharath Institute of Higher Education and Research, \\ Chennai, India, \\ drvr@bharathuniv.ac.in
}

Corresponding author: R. Varatharajan

\begin{abstract}
Water is the primary resource for all living beings globally and its efficient harnessing is key to achieve a rational and fair distribution. In this work, a smart drinking water management strategy for water supply based on sensors, comparator circuits, PLC (Programmable logic control) and fuzzy logic is suggested to control the water supply in order to reduce water usage and achieve an equative sharing. In the previous methods in the field, the conventional algorithm technique based on the water distribution and management system cannot easily interface with sensor devices in the water distribution method. Therefore, an improved fuzzy rule set distributed algorithm based smart water management system using programmable logic control is proposed in this work. More specifically, the suggested technique integrates a flow meter, a solenoid valve and IoT (Internet of thing) based digital code algorithm. In order to analyzed its validity, the proposed smart water management system is simulated and also, a hardware prototype is developed. Results show that this system can manage the monthly usage of water levels with $90 \%$ efficiency compared to the existing method. Also, the system integrates a $\mathrm{pH}$ sensor to test the water quality and distribution and support clean water-oriented processes.
\end{abstract}

Key Words and Phrases: IoT, water management system, PLC (programmable logic control), improved fuzzy rule set distributed algorithm, digital code algorithm 


\section{INTRODUCTION}

The demand for water in growing urban infrastructure is increasing multifold. Water management refers to many sources, including leaks, artificial laziness, and labor errors. There is also the issue of unequal water supply. An algorithm based on programmable control is used to control the water supply to reduce water usage. Monitoring water resources can effectively prevent water levels. Therefore, in recent years, urban water supply monitoring systems have attracted attention. The water frame is the link between the drinking water supply and the drinking water consumers. Since the water supply system is an essential component, it is designed to provide uninterrupted water supply, water quality management, monitoring, and maintenance. Technical parameters like identifying water usage and addressing limitations caused by water availability, water conditions, the storage capacity of water tanks and water towers, and diversification of water consumption are to be monitored. The system includes logical control and $\mathrm{pH}$ sensor and flow sensor. Also, the system method consists of one or more central automation master stations that communicate with one or more automation processes connected to the distribution system. Programmable logic control maintains direct control over physical components, the control command system.

An evolving distribution method, drinking water, creation, recreation, and gardening, is expressly excluded about freshwater. Gatherings Water Management is an open-gate system to the Water method and Water Flow method engineering. It seeks to give every quarter's addresses and strongly distributes executives to undertake noticeable progress with the business. The motivation behind board applications is to discuss building standards and the implications for development. Currently, our primary testing goal is to improve and facilitate improved and faster design implementation measurements.

Contrary to the attributes created by others, the exercise of our water board on the opportunity to cooperate directly. Another water board alternative is sector mandate on water. The legislature facilitates water to everyone at a moderate rate. This method of measuring the water used by people is called flow metering using water distribution.

In many apartment sectors, water meters are used in residential or commercial buildings provided by public water supply systems to measure the system to determine the flow through a 
specific part of the system. Furthermore, due to query administration, applications are delayed to make innovations realistic and improve and expand administrations. Unlike privately owned businesses, if the administration neglects to control water simply, the legislature has a responsibility and, in these ways, must take care of the human rights of individuals. The relevant human reason perceived through work is a rational choice for water. Some sectors can guarantee that this right will not be neglected by giving water to everyone. Hence, this work contributes to the efficient harnessing and fair supply of water by considering the combination of novel technologies involving IoT and fuzzy logic.

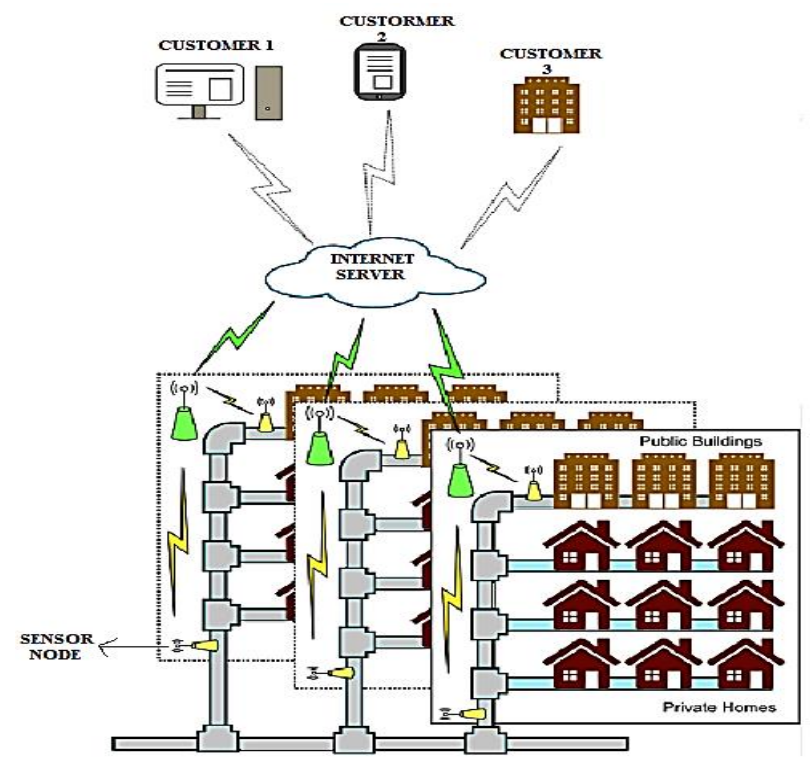

Figure 1 Module of water distribution system using IoT

This work is organized as follows. In section 2, the previous works in the field are analyzed and discussed to emphasize the need for the proposed strategy. Next, in section 3, the materials and methods integrating the proposal are presented. In section 4, the obtained results are presented and discussed. Finally, in section 5, the main conclusions of the work are drawn.

\section{PREVIOUS RESEARCH WORK}

The operating method of modern water distribution systems has increased in recent developments. Significant research has been conducted on the combined analysis, planning, and operation of integrated energy, natural resources, and water energy system to explore potential 
synergistic benefits from multi-application consumption [1]. Water is a critical asset to the singular human and its reality. The population of urban areas is rapidly expanding due to the specific measure of individual movements from one country zone to urban zones [2]. A prototype is proposed to improve the charisma compatibility of water transport frameworks in energy frameworks. Water sprinkler framework operators who run the current operational model are considered to upgrade the siphons and tanks' service to limit the limit of the neighboring water distribution system, general water request [3]. As correspondence progresses, the framework for consistently monitoring pipe water quality is gaining more importance. This work describes the ongoing progress in the field of in-pipe continuous defilement identification framework [4].

Similarly, the pollution position framework is created based on the growing Internet of Things innovation [5]. It includes a robust, minimal effort framework for spill detection in urban water supply pipes. Our current automated structure is designed to detect holes in our low spill rates. There is a need for different design strategies being used today to make the most [6].

The rancher controls the engine from going to field areas. When the water level is likely to expand at a threat level, the driver is typically shut down without the rancher [7]. The infrared picture area is assumed to be entirely memorable for the visible film, and the interpretation between the regular scenes in the two images may vary slightly and point through. Still, some scope contrast may also be available [8]. Water distribution is a significant factor in the prosperity of the water occupation and the extraordinary impact on the economic sector. In some areas where weather conditions change significantly, water system offices are scarce [9]. Water distribution is convenient and adequate with water. Water siphons are crucial in energy water distribution. Another strategy was introduced i.e., programmable control-based impedance spectroscopy, which is adjusted explicitly for biometric sensor readout [10].

The on-board sound equipment of an advanced cell or personal device can be used to perform impedance estimates, although full client control is provided by the application's methods [11]. A measured plan plans the sensor, and its optimal position has minimum structure and low volume. The hub can collect soil temperature data and send it to the upper system hub. Forced correspondence separation and blunder code rates are wide fields [12]. Municipal 
corporations broadly classify waste into two categories: dry waste and water waste [13]. Many waste collection agencies have difficulty separating dry and water waste due to a lack of public awareness [14]. All water waste is degradable, while dry waste is not degradable; it is essential to separate non-degradable and degradable waste [15]. There are three different sensors in the system. It was used for water level identification. One is placed at the bottom of the capacity, the second in the middle of the tank, and the third at the end of flow [16]. If the water level detector detects a low or medium level, the Programmed logic control pump station will turn on the motor [17-18]. If there are some minor leakages in the system and more water due to lack of civic sense are the main drawbacks of the previous work. The water network is very large and consists of various components (pipes, pumps, valves, etc.). As they get older, they are more prone to failures and leakages, and their performance and efficiency will come down. The water network is extensive and inconvenient for transportation [19-20].

Hence, in view of the lacks of the previous works in the area, a new smart water supply method is presented and analyzed in the following sections [21-23].

\section{MATERIALS AND METHODS}

In the proposed method, the analog data's measure by all the sensors is sent to the controller for automation water distribution processes. After processing the digital information in the algorithm unit where analysis is done, and the water quality is identified, those parameters were sent to the person operating with the Internet of Things. The flow meter absorbs the water flow continuously from the pipe by using a solenoid valve based on the received data. Flowmeter was calculating water level per liter unit continuously measures the amount of water-based on the limit. Also, the water level's value will continue to decline until it reaches a specific threshold, and the water supply is shut off. $\mathrm{PH}$ is a measure of the acidity or essential alkalinity of water, defined as the negative log of ration as a hydrogen ion. This digital meter is a digital type that gives an accurate reading. Blocks in Figure 2 shows the proposed block diagram of this method. 


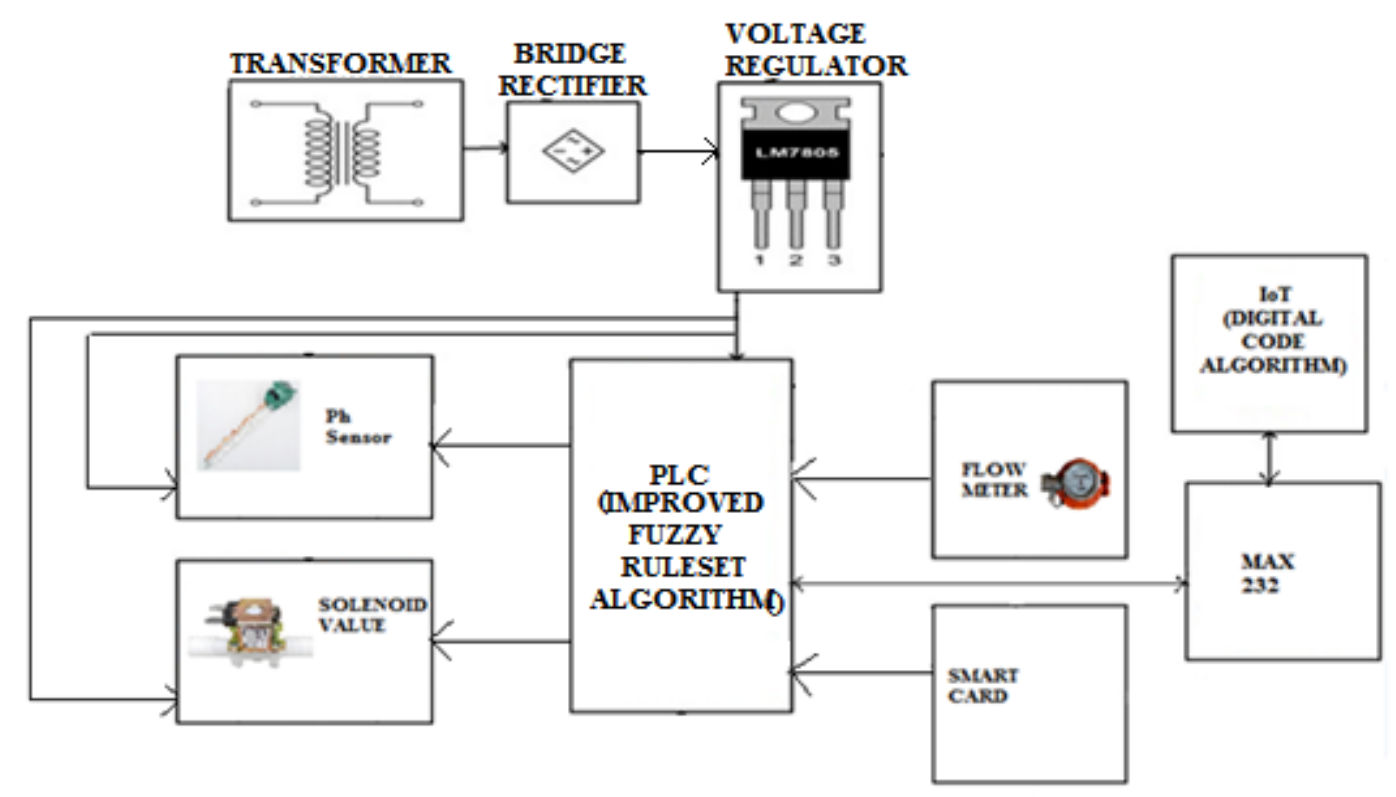

Figure 2 Proposed Block Diagram

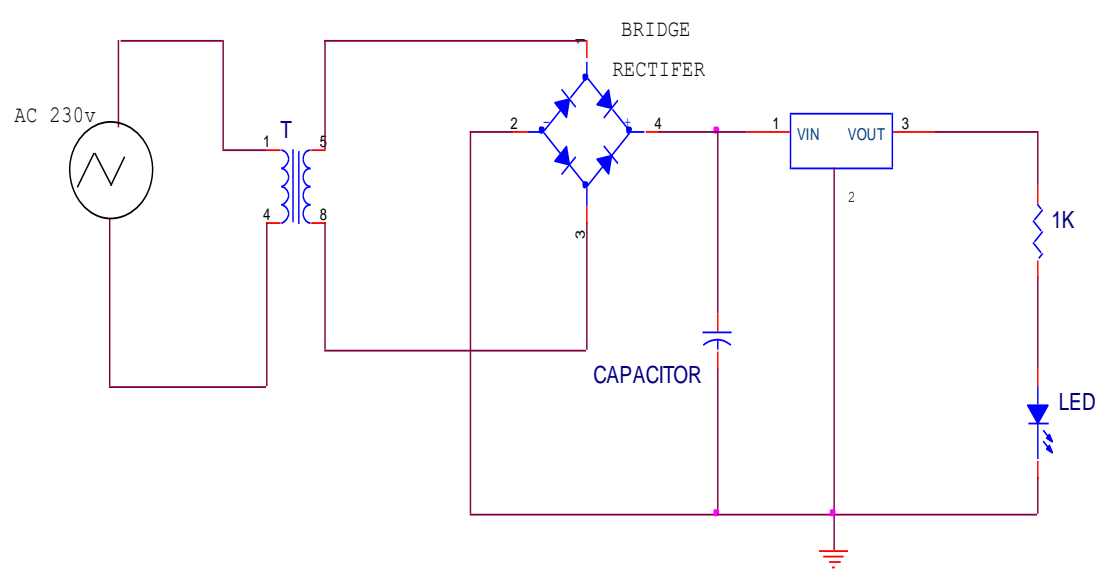

Figure 3 Circuit Diagram of power supply

\subsection{POWER SUPPLY}

Direct current power is still required for small appliances and circuits and active input source structures used in transmission and conversion circuits and most electronic circuits. Small devices and circuits used in transmission and conversion circuits are required and most electronic circuits require efficient input source structures and a Direct current power supply. They are unpredictable, free, and flexible waves. If their working voltage is still low, they were once 
replaced and are now more expensive than a traditional direct current power supply. Today, almost all input sources from the distribution grid are Alternative current power, which is converted into direct current electricity. Some devices are called as alternative flexible digital power supplies that can be converted to current coordinates. Figure 3 represents the converting alternating current to direct current.

\subsection{SOLENOID VALUE}

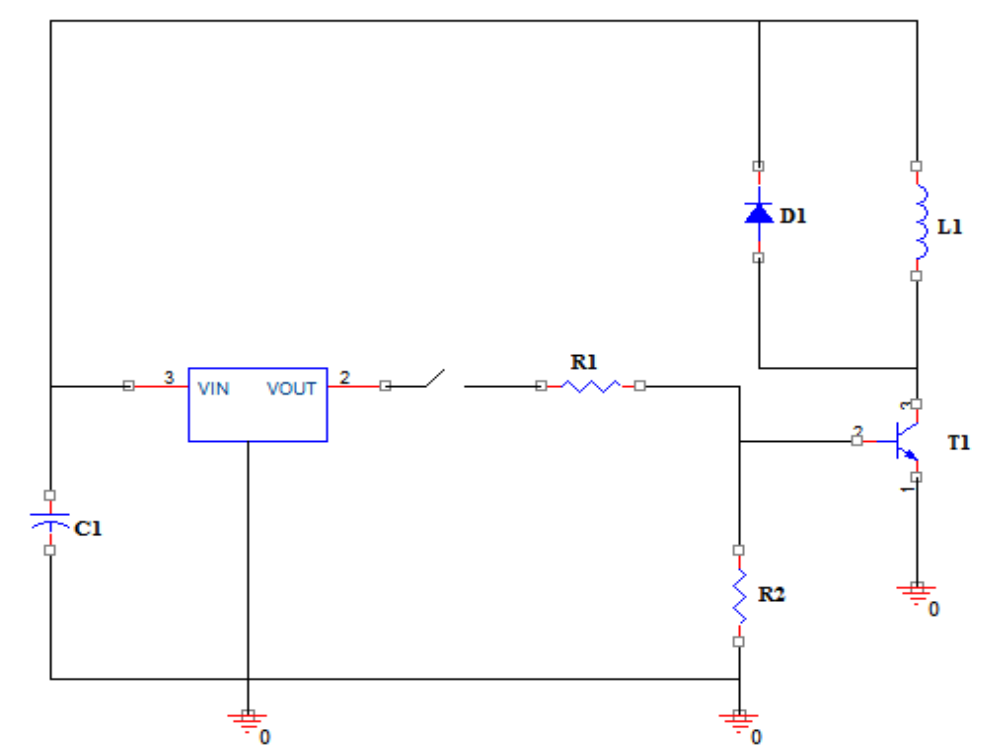

Figure 4 Circuit diagram of the solenoid valve

The water flow in the pipe controls the figure 4 solenoid valve. The electromagnetic effect of the magnetic field coil causes the plunger to move inside the material. Depending on the valve's valve design, usually on or mostly off type, when the piston is opened by applying current to the pipe, and the water flow is controlled by the solenoid valve used in the model. The most commonly used control element in fluid engineering is the solenoid valve. The solenoid is designed for fast and safe switching, high reliability, and longevity, excellent media compatibility of the materials used, low power consumption control, and compact design.

\subsection{Improved Fuzzy Ruleset Distributed Algorithm}


The improved fuzzy rule set distributed algorithm is a random technique that minimizes the natural evolutionary process. This method is used for optimization, and computing systems continue to improve and it is useful for error control with optimization of analog processes from digital. The correct solution to fault control technology is known. It depends entirely on the responses to its environment, and evolution operators reach the best solution, such as reproduction, crossover, and desired value. Starting from several independent points and searching in parallel, the algorithm becomes a subset different from the local minimum. The incorrect distribution algorithm consists of the following steps.

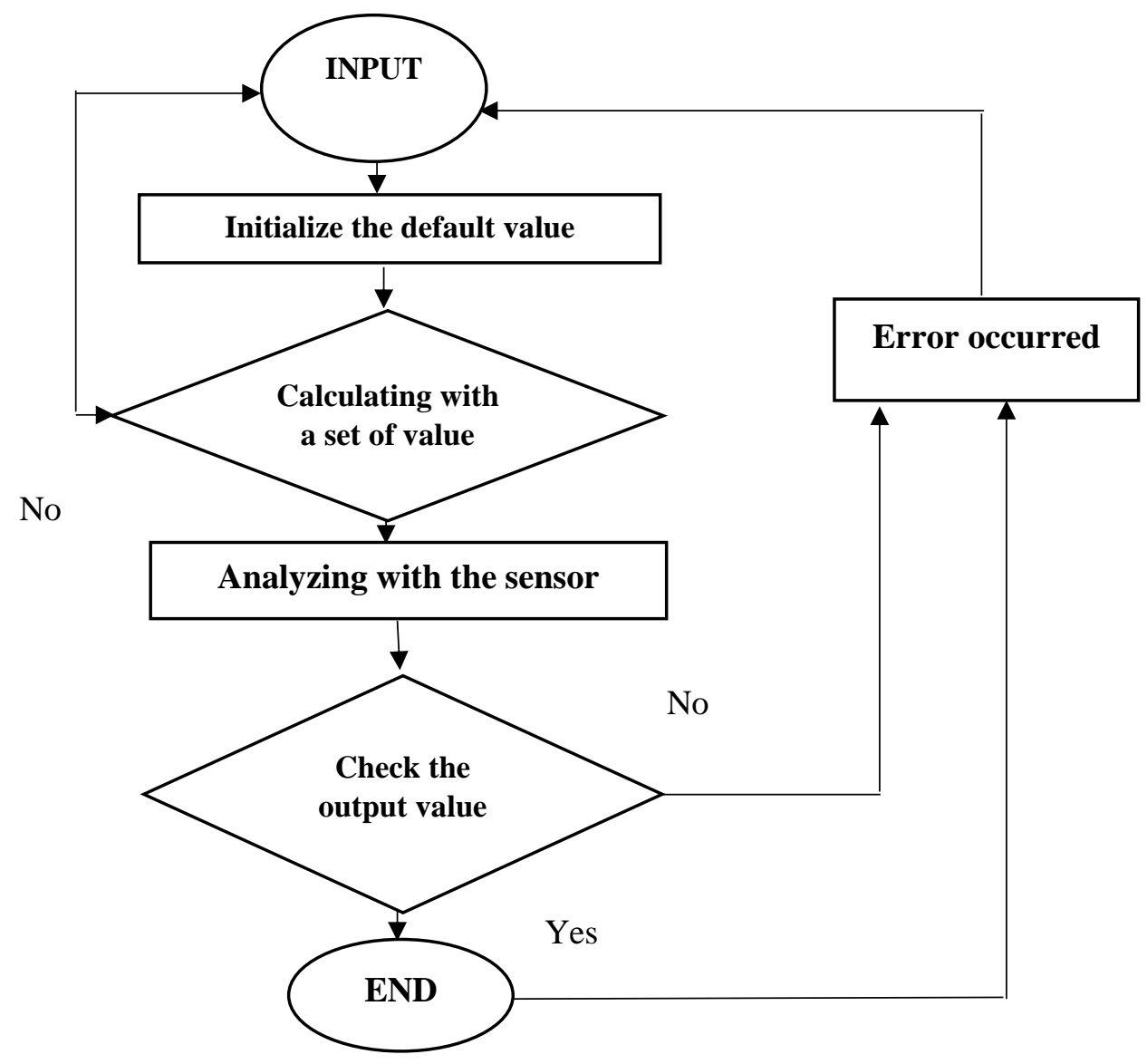

Figure.5 Flow chart of PLC based controller algorithm.

Step 1: Start.

Step 2: To find a balanced value at the end of the load, must cancel the imbalance of the system voltage, therefore, 


$$
\begin{aligned}
& V_{L}(t)=V_{s}(t)+V_{c}(t) \\
& V_{c 0}=V_{s 0}, V_{c-}=-V_{s-1}
\end{aligned}
$$

$V_{L}$ Is a definite sequence, $V_{c}$ is injected positive sequence voltage.

Step 3: To obtain a uniform system currently, the injected current must be zero, and the line component of the load current is obtained.

$$
\begin{aligned}
& i_{L}(t)=i_{s}(t)+i_{c}(t) \\
& I_{c 0}=I_{L 0}, I_{c}=0, I_{c-}=I_{L}
\end{aligned}
$$

Where $I_{L o}$ the definite sequence of the sensor values and $I_{c 0}$ is the negative sequence of sensor value.

Step 5: The average value of this function and the Figure 5 flow chart of the filter's output depends on the actual power consumption of the positive terminal.

Step 6: End.

\subsection{PH Sensor}

The $\mathrm{pH}$ value is a numerical representation of the hydrogen ion concentration per gram equivalent to any solution. It measures the number of moles of hydrogen ions per liter of solution. Measuring $\mathrm{pH}$ will measure the alkalinity or acidity of a solution. Because water consumption is priced based on volume prices, it provides an incentive for quantity to save water. It also helps maintain an utterly low-quality distribution network, as water distribution and mitigation can be done effectively. Its installation may be a fundamental process for protecting and water management of the water utility system on this planet.

\subsubsection{PH sensor specification}

$>\mathrm{PH}$ resolution $0.01 \mathrm{PH}$.

$>\mathrm{PH}$ accuracy 0.02

$>$ Temperature range -5.0 to 60.0 deg. Celsius. 
Response time $<=1$ minute.

\subsection{Internet of Things}

The system focuses on the water crisis and makes water distribution more efficient, mainly by reducing water and electricity waste. The proposal has been promoted in rural and urban areas considering water distribution systems. This system distributes water evenly throughout the city/region. It monitors, controls, and protects all water pumps for water distribution purposes. It can monitor all storage tanks and is equally dependent on the amount of water to be distributed in the tank area

Open standards promote the operating system, but little is known about the strategies that need to be implemented to create standards that allow a certain functional openness level. Therefore, this study examines the innovation strategies followed by open benchmarking participants and how it affects innovation. Exploratory research has been done by applying a complex theoretical framework, popular design principles, benchmarking principles, and theoretical framework to integrate critical users.

Strategies are being created by middleware that allows devices that work on different technologies to connect, learn from users, and enable full interoperability of open-source platforms. The open nature of the IoT leads to creating dominant configurations in which its components can change order depending on the context. It has implications for innovation. The Internet's subject is not a unified industry in which the dominant design leads to increasing innovations, change from connecting components.

\subsubsection{Digital Code Algorithm}

The automation of the application framework and the Internet of Things are applied in this algorithm. It assumes that the framework is a jump away from the sink. It is said that the data receiver is located close to the encoded, using multiple data sinks in deployment to cover a larger area and is sufficiently robust and therefore has a more extended transmission range by either relying on facts to achieve. It also assumes that the cluster heads are within range of each other. Please note that these assumptions do not affect the generality of the proposed clustering 
mechanism. They have greatly simplified the way they communicate with the sink because no routing mechanism is needed.

Stage 1: The input sensor data are read from the level of a management system

$$
p(a)=\sum_{i=1}^{N} \pi(d i j<d o]
$$

Here $\pi$ is the information point Mixture with $\mathrm{I}$ is the Gaussian group segment coefficient. Contingent upon it, the scope of qualities among 0 and Clusters, and the total of all blending factors is equivalent to 1 . MI is the all-out normal of Gaussian groups is the covariance. Also, $\mathrm{N}$ speaks to the absolute number Chosen group.

Stage 2: Analyst specifies analog to the digital value of the controller technique of partition data.

$$
d_{i j}=p(a) \exp (i \emptyset r)
$$

$\mathrm{d}_{\mathrm{ij}}$ - wireless communication device between sensor $\mathrm{i}$ and $\mathrm{j}$ and $\mathrm{p}(\mathrm{a})=$ analyzing networking value

Stage 3: Transfer the next level of networking processes centers

Stage 4: For each record, Find value centers the center of each subset of records

Step 5: For each center, the data finds a mean value update cluster center location to the centroid, where $K_{\max }$ is the maximum level of sensor value of the prototype method.

$$
K_{\max }=p(a) \exp (i \emptyset r)(i j \neq 1)
$$

Step 6: For comparing sample sensor data, repeat steps 1-3 condition for each thermal image for various processes technique, and Figure 6 shows the flow chart of algorithm frame processes technique using IoT.

\subsection{Water Level Sensor}


The water level sensor is a flow of water detecting sensor obtained by measuring a value level with a series of parallel wires to reveal the water level.

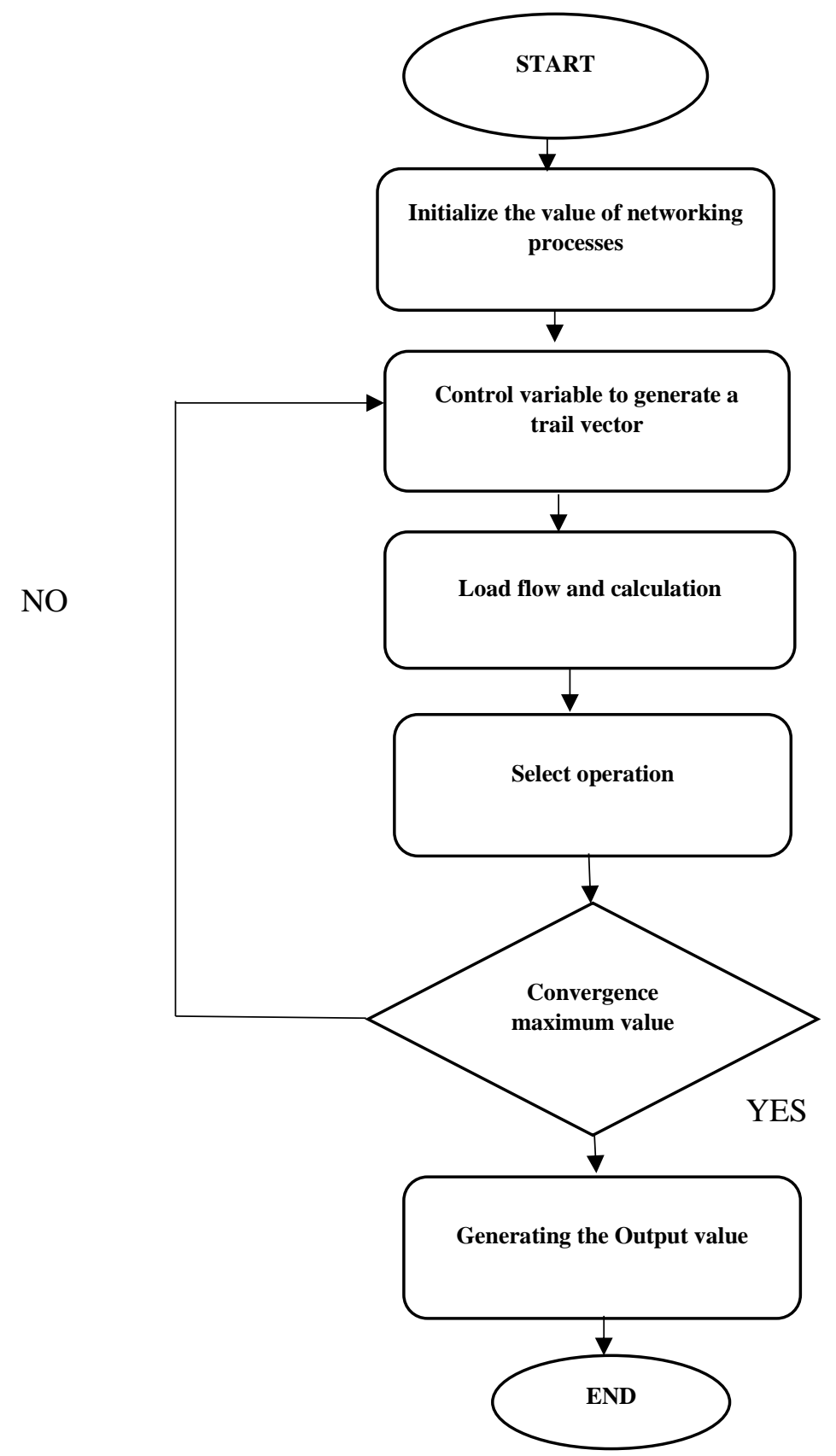

Figure 6 Flow chart of IoT (digital code algorithm)

It is convenient to convert the whole data into analog signals and output the analog values. The liquid state alarm effect realized by the Control Development Board can be read directly. Water level sensors are used to monitor and control the amount of material flowing 
freely in one place. Various types of fluid level sensors are used to detect the point of the fluid. Some variants use magnetic floats, which rise in the container with liquid. Figure 7 shows the water level sensor and components connect to the value of water that detects.

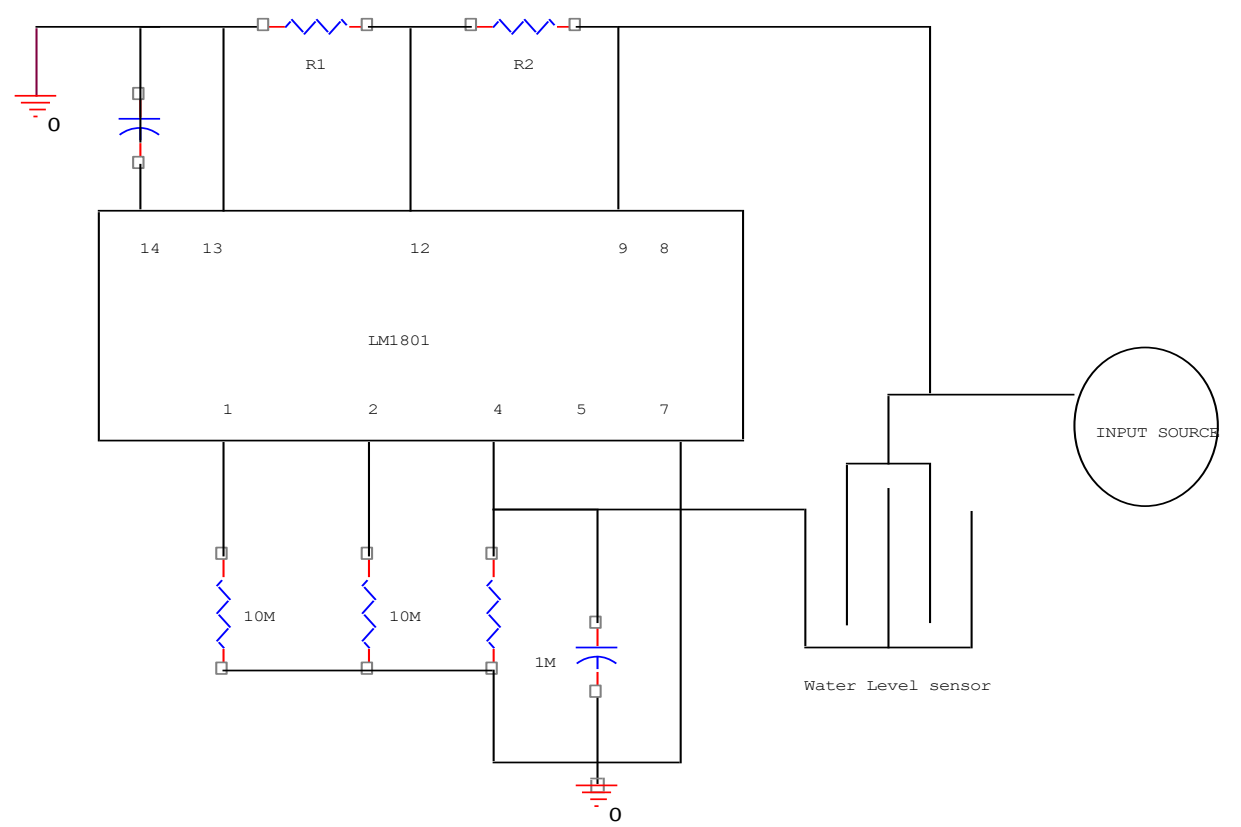

Figure 7 Circuit diagram of water level sensor

\subsubsection{Water Level specification}

$>+$ stands for $\quad+5 \mathrm{~V}$

- stands for GND

$\mathrm{S}$ stands for signal

\section{RESULTS AND DISCUSSION}

As shown in Figure 8, the simulation output contains a proteus circuit that includes a water level sensor, $\mathrm{Ph}$ sensor, solenoid valve, and motor and water flow measure up to 20 liters to a limited value.

Figure 9 gives the continuous level sensors measure level within a specified range and determines the exact amount of substance in a particular place. In contrast, point-level sensors 
only indicate whether the meaning is above or below the sensing point. Generally, the latter detect levels that are excessively high or low.

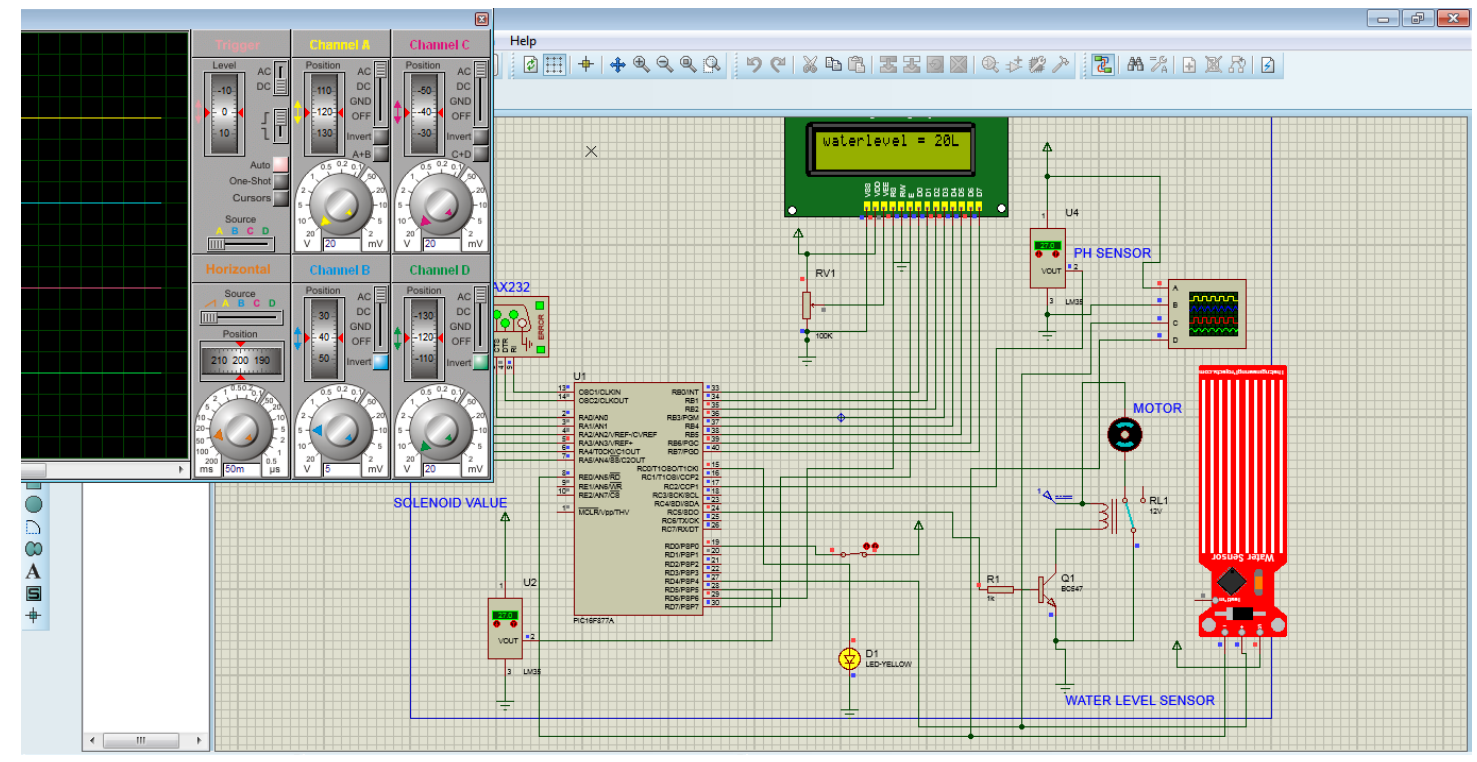

Figure 8 Smart Water Management System simulated circuit

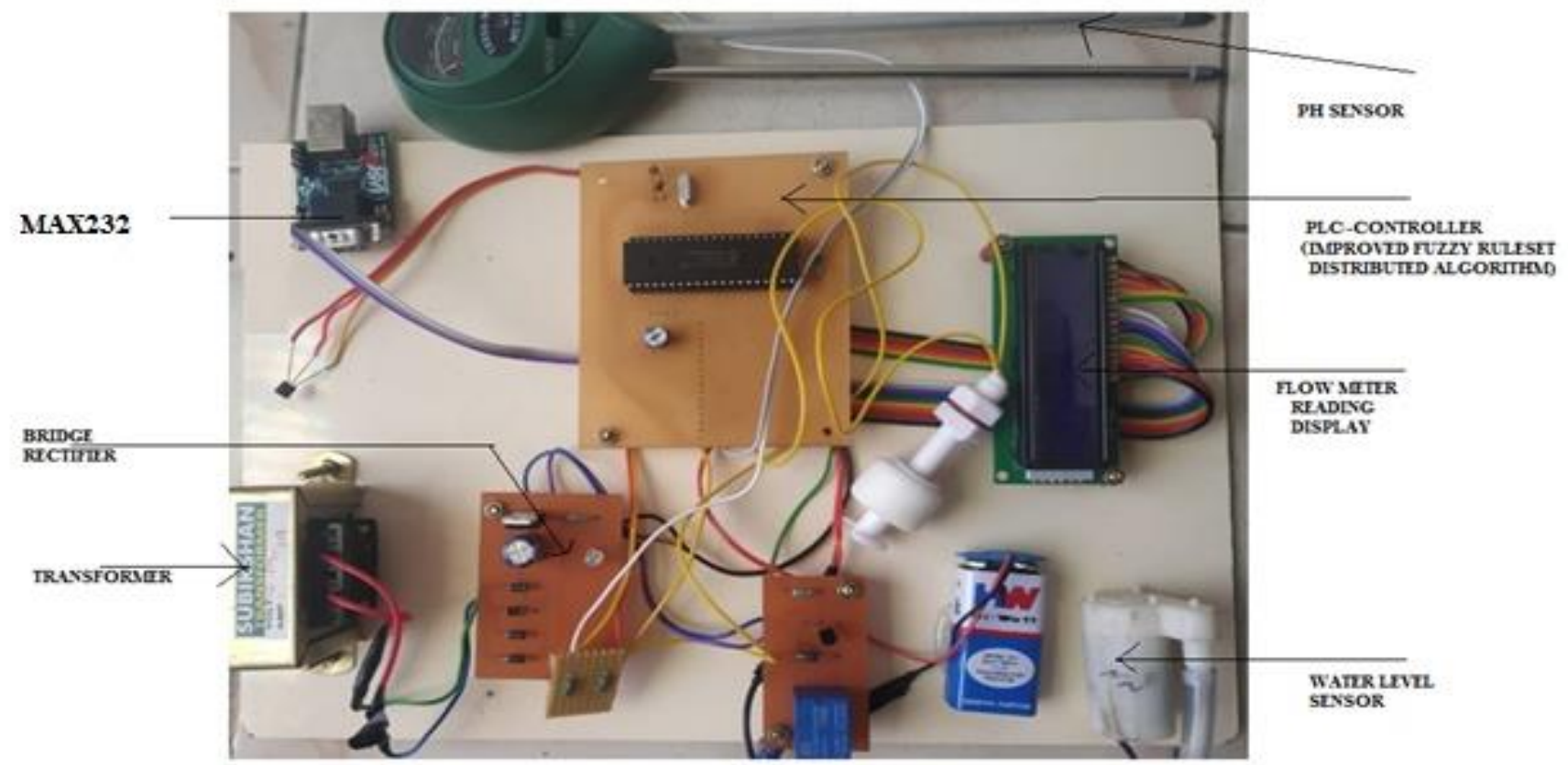

Figure 9 Prototype type output model of the water distribution system. 


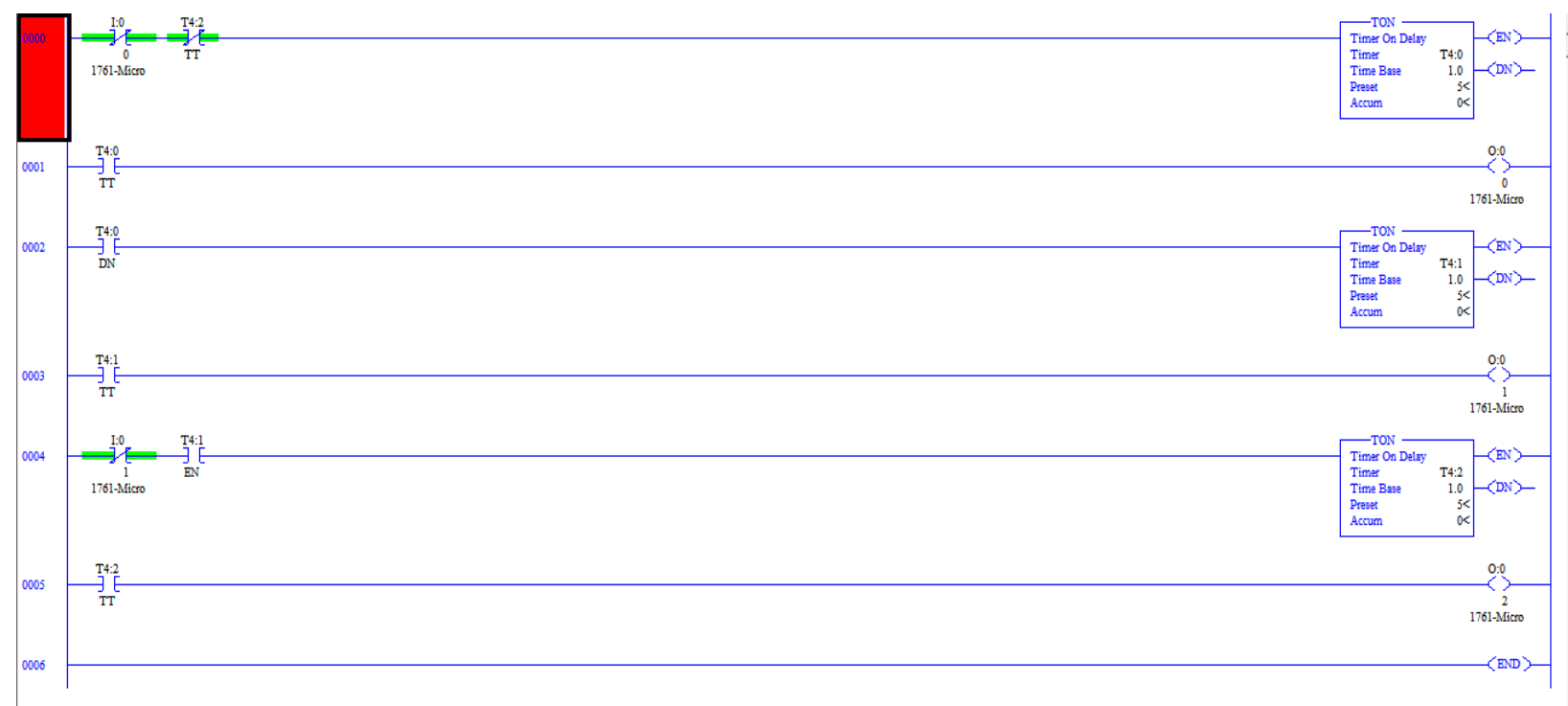

Figure 10 the Ladder Diagram of PLC Output of Water Distribution System

Additionally, Figure 10 shows the ladder diagram of PLC output of water distribution system. The ladder diagram of a water distribution system simulates the closing process of opening an on and off in open and close condition. It is extended to include ladder logic programming function operations such as timer on and time off and shift registers and arithmetic.

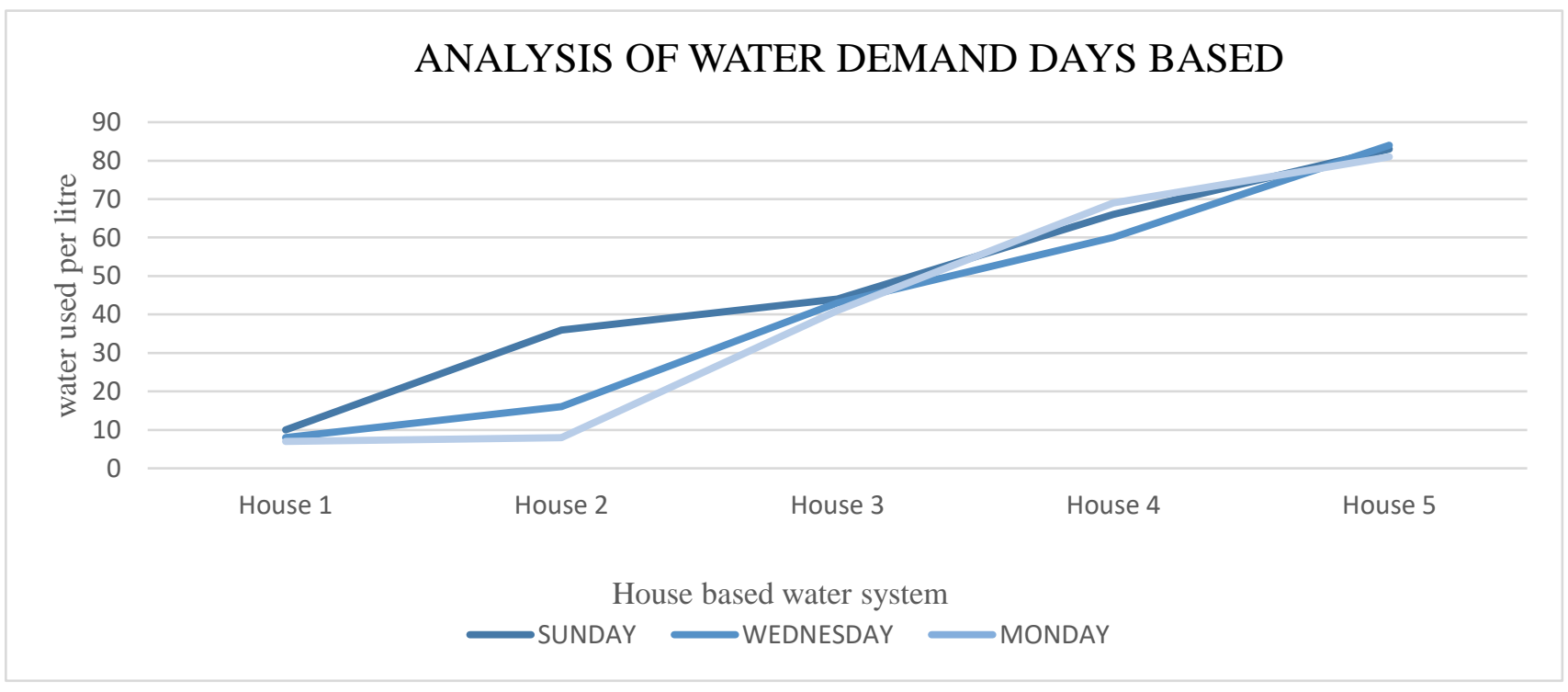

Figure 11 Analysis of Water Demand Days Based. 
Also, Figure 11 shows the comparison chart of maximum water demand using sensor. A model for water distribution system using weekdays. This system has taken limit 80-liter average value of weekly three days.

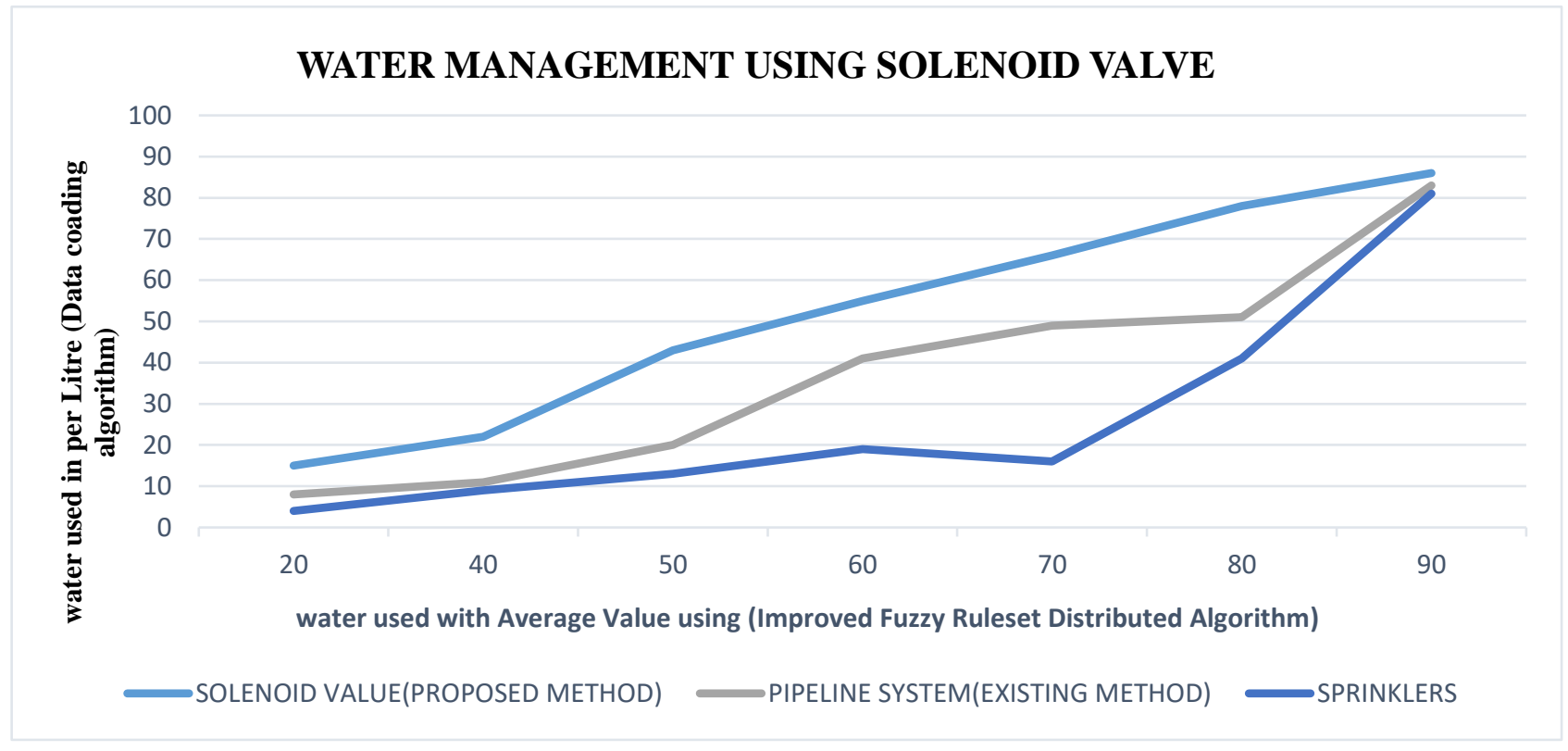

\section{Figure 12 Water Management Using Solenoid Valve}

Figure 12 shows the comparison chart of solenoid valve with improved fuzzy ruleset distributed algorithm comparison of a solenoid value-based average value is 100 liters, and the distribution system is a comparison of the flow of water through the different techniques.

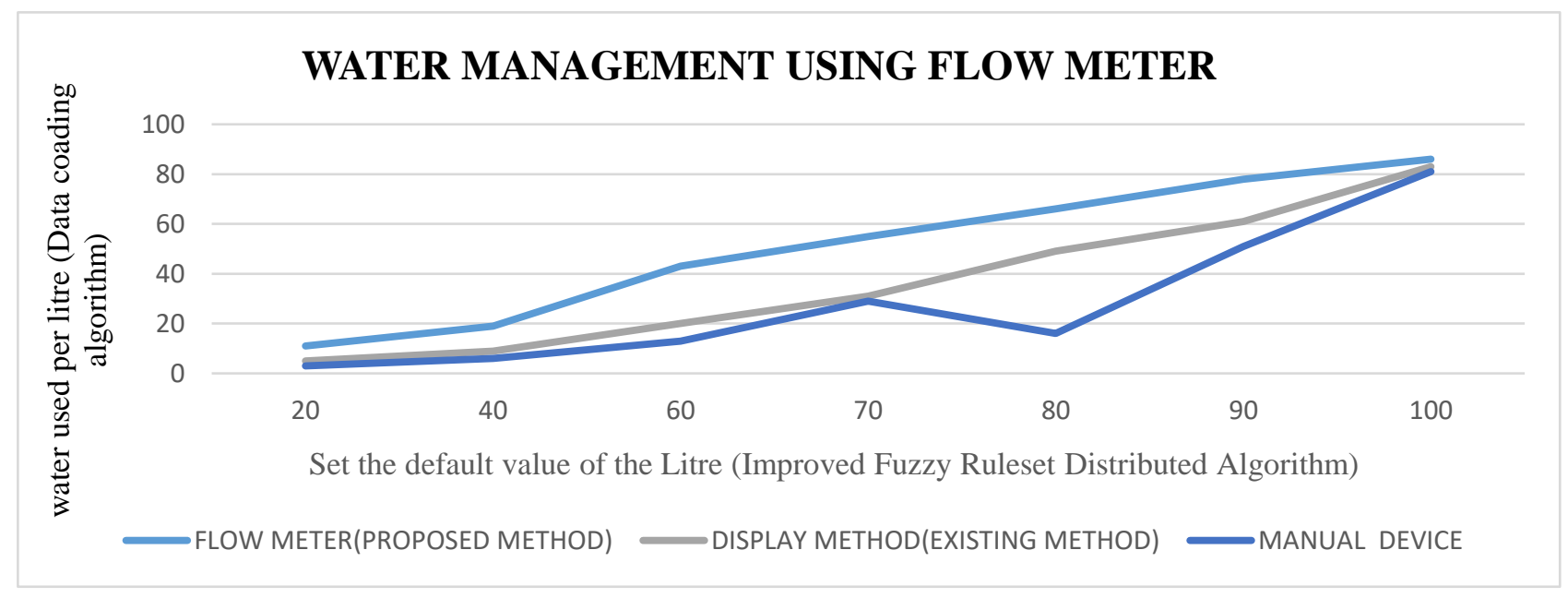

Figure 13 Water Management Using Flow Meter 
Furthermore, Figure 13 shows the comparison for a flow meter-based water distribution system, and the flow of water is 100 liters calculated the current average value analyzed.

Table 1 Analysis of the value measured in distance and time by calculating method using the SMS notification.

\begin{tabular}{|c|c|c|c|c|c|}
\hline S.NO & $\begin{array}{l}\text { ADVAREGARE } \\
\text { HOUSE IN } \\
\text { APARTMENT } \\
\text { WITH ID }\end{array}$ & $\begin{array}{c}\text { FLOW } \\
\text { METER } \\
\text { VALUE } \\
\text { READING }\end{array}$ & $\begin{array}{c}\text { PH } \\
\text { SENSOR } \\
\text { READING }\end{array}$ & $\begin{array}{c}\text { PAYMENT } \\
\text { STATUS }\end{array}$ & $\begin{array}{c}\text { LIMITS } \\
\text { OF EACH } \\
\text { AND EVERY } \\
\text { HOUSE }\end{array}$ \\
\hline 1 & HOUSE 1 (ID 9255) & 4 & 1 & $\begin{array}{l}\text { Payment } \\
\text { collected }\end{array}$ & 10 \\
\hline 2 & HOUSE 1 (ID 9256) & 12 & 2.2 & $\begin{array}{l}\text { Payment } \\
\text { collected }\end{array}$ & 20 \\
\hline 3 & HOUSE 1 (ID 9257) & 5 & 2 & $\begin{array}{l}\text { Payment } \\
\text { collected }\end{array}$ & 10 \\
\hline 4 & HOUSE 1 (ID 9258) & 15 & 1.3 & $\begin{array}{l}\text { Payment } \\
\text { collected }\end{array}$ & 25 \\
\hline 5 & HOUSE 1 (ID 9259) & 20 & 2 & $\begin{array}{l}\text { Payment } \\
\text { collected }\end{array}$ & 30 \\
\hline 6 & HOUSE 1 (ID 9260) & 19 & 2.5 & $\begin{array}{l}\text { Payment } \\
\text { collected }\end{array}$ & 25 \\
\hline
\end{tabular}

Table 1 shows the parameters of flow meter, PH sensor, payment status, and each house's limits.

Table 2 Compression Table of Proposed PLC Based Algorithm Technique 


\begin{tabular}{|c|c|c|}
\hline & $\begin{array}{r}\text { Improved Fuzzy Ruleset Distributed } \\
\text { Algorithm }\end{array}$ & Backpropagation Algorithm \\
\hline $\mathbf{1}$ & $\begin{array}{r}\text { The method is used for both Automation } \\
\text { and Manual processes }\end{array}$ & $\begin{array}{c}\text { This method is suitable for only } \\
\text { manually processes }\end{array}$ \\
\hline $\mathbf{2}$ & Data are accuracy and transferable & $\begin{array}{c}\text { Data are not accuracy and } \\
\text { transferable in limit accesses }\end{array}$ \\
\hline $\mathbf{3}$ & Sensors are easily suitable for & $\begin{array}{c}\text { Some sensors are not readily } \\
\text { suitable for this Algorithm } \\
\text { In this Algorithm }\end{array}$
\end{tabular}

Also, Table 2 shows the comparison table of the existing and proposed method using programmable logic control-based algorithm technique and analyze different parameters.

Table 3 Compression Table of IoT based Algorithm Technique

\begin{tabular}{|c|c|c|}
\hline S.N0 & $\begin{array}{c}\text { (Proposed Method) } \\
\text { Digital Code Algorithm }\end{array}$ & $\begin{array}{r}\text { (Existing Method) } \\
\text { Levenberg-Marquardt Back- } \\
\text { Propagation Algorithm }\end{array}$ \\
\hline $\mathbf{1}$ & End to End communication & End to Device Communication \\
\hline $\mathbf{2}$ & It needs Internet protocol for & Unsecured communication \\
& communication and stored data for secured & and cannot monitoring easily \\
\hline $\mathbf{3}$ & communication & Open source can quickly occur \\
\hline
\end{tabular}

Finally, Table 3 shows the comparison table of existing and proposed methods using IoT based algorithm technique and analyzed different methods. 
Hence, as it can be inferred from the presented graphs, data and analysis, the proposal outperforms the existing method in the different studied aspects, and thus, its major efficiency for water supply.

\section{CONCLUSIONS}

The automated system provides a continuous flow of water according to the set point. The project is automatic because it reduces a lot of human resources. Automation means a reduction in wasting water, saving time, and ensuring implementation in the water supply system. At the same time, this method can ultimately improve the water distribution system, in a way that users can get an equal share of water. The system is based on a water consumption calculation principle and charges a corresponding tariff to consumers. Water from the credit amount per number of users will load the credit meter by technology and powered by the Internet of Things technology. It can manage the monthly usage of water levels with $90 \%$ efficiency compared to the existing method.

\section{REFERENCE}

[1]. Li, X., Zhao, X., \& Yang, L. " Water flow analysis of combined power-regional integrated electricity and water networks, IEEE Conference on "Internet and Energy System Integration".2018

[2]. Mr. M. M. Srihari " Intelligent water distribution and management system using the Internet of Things "International Conference on Research in Computing Applications ".2018

[3]. Oikonomou, K., \& Parvania, M. "Proper coordination of water distribution power facility with Power Systems operation” IEEE Transactions on the Smart Grid, 2018

[4]. Priya, S. K., Shenbagalakshmi, G., "Real time in-pipe pollution detection system in drinking water" International Conference Communication and Signal Processing.2018

[5]. Dvajasvie, G, "Leak detection in water supply pipe systems" Second International Conference on Intelligent Computing and Control Systems.

[6]. Mr. M. A. Murtaza, Mr. Mragank Sharma, "Microcontroller Solar Powered Automatic Irrigation System "2017. 
[7]. X. Wang, W. Yang, A. " E_cient registration of optical and IR images for automatic plant water stress assessment " Compute. Electron. Agriculture. Vol. 74, No. 2, Year, 2016.

[8]. Venkata Narayana Eluri, K. "Wireless solution to save water in agriculture using embedded system."

[9]. J. Broeders, D. Croux, "Mobile application for impedance-based biometric sensor readout "IEEE Sensors J., Vol.13, No. 7, Pp. 2659-2665 July 2013.

[10]. Xihai Zhang, " Design and execution of signals based on farm information wireless monitoring " IEEE.2018

[11]. Rashmi M.Kittali and Ashok Sutagundar, "Automation of waste segregation system using PLC, "International Journal on Emerging Technologies."

[12]. Ashish Chougule, "Automation Distributed System Testing Water in Drinking Water Supply Using PLC," IOSR Journal of Electronics \& Communication Engineering (IOSRJECE)

[13]. Pooja Narkhede, "Water level monitoring using PLC," International Journal of Research in Advent Technology. 2016

[14]. Aunbhapanchal, "Water theft detection using Automated Water Supply System \& PLC and SCADA, "International Journal of Engineering Research and Applications, April 2014

[15]. Ramleela Khare, "Automation of Water Distribution Plant" International Journal of Research in Engineering and Advanced Technology, 2014.

[16]. Gowtham.R, Varunkumar M.C. “Automation in self-power generation in urban drinking water filtration, water supply control, water theft detection and supply control system using PLC and SCADA".2014

[17]. Ullah, Rehmat | Afzal, Muhammad Khalil | Kim, Byung-Seo, A novel parallel processing mechanism for data transmission in wireless content-centric networking, Journal of Intelligent \& Fuzzy Systems, vol. 35, no. 6, pp. 5815-5825, 2018

[18]. T. Baranidharan, A.Chinnaduri, "Automated water distribution system using PLC and SCADA," International Journal of Electrical and Electronics Engineers. 2015

[19]. Nicholas, Lee et al. 'Study of Long Short-term Memory in Flow-based Network Intrusion Detection System', Journal of Intelligent \& Fuzzy Systems - Volume 35, issue 6, 1 Jan. 2018, pp. 5947 - 5957. 
[20]. Eswaran.P, \& Aswin Kumar; "Conceptual Design and Development of Water Metering System for Multiple-family Residential Buildings," International Journal of Advanced Computer Research, 2012.

[21]. Gaikwad Sonali Ashok; "Water Anti-theft and Quality Monitoring System by Using PLC \& SCADA," International Journal of Electrical and Electronics Engineering Research. June 2013.

[22]. Park, Young-Hoon. 'Key Management and Data Re-encryption Schemes for Secure Invehicle Network', Journal of Intelligent \& Fuzzy Systems - Volume 35, issue 6, 1 Jan. 2018, pp. $6079-6087$.

[23]. Bhawarkr.N.B, Pande.D.P, "Literary review for automated water supply with monitoring performance system,” International Journal of Current Engineering and Technology, 2014. 